\title{
Growth responses of the marine photosynthetic ciliate Myrionecta rubra to different cryptomonad strains
}

\author{
Jong S. Park ${ }^{1}$, Geumog Myung ${ }^{2}$, Hyung S. Kim ${ }^{3}$, Byung C. Cho ${ }^{1}$, Wonho Yih ${ }^{2, *}$ \\ ${ }^{1}$ Molecular and Microbial Ecology Laboratory, School of Earth and Environmental Sciences, Seoul National University, \\ Seoul 151-742, ROK \\ ${ }^{2}$ Department of Oceanography, Kunsan National University, San 68, Miryong-dong, Gunsan 573-701, ROK \\ ${ }^{3}$ Gunsan Regional Maritime Affairs and Fisheries office, MOMAF, Gunsan 573-882, ROK
}

\begin{abstract}
The photosynthetic Myrionecta rubra (=Mesodinium rubrum) is a cosmopolitan ciliate that frequently feeds on free-living cryptomonad species in diverse marine environments. Hence, $M$. rubra might feed on a wide range of cryptomonad species. To explore this possibility, we investigated the growth responses of $M$. rubra strain MR-MAL01, which was starved for 20 d, to diverse cryptomonad strains CR-MAL01, CR-MAL02, CR-MAL03, CR-MAL04, CR-MAL05, and CR-MAL06. Phylogenetic analysis of the aligned 18S rRNA sequences from cryptomonads suggested that the strains CR-MAL01, CR-MAL02, CR-MAL04, and CR-MAL05 were included in cryptomonad Clade 2, while the strains CR-MAL06 and CR-MAL03 were included in cryptomonad Clade 3, with high bootstrap value $(98 \%)$ and posterior probability of 1 . Intriguingly, $M$. rubra strain MR-MAL01 grew better in the presence of cryptomonad strains CR-MAL01, CR-MAL02, CR-MAL03, CR-MAL04, and CRMAL05 (0.16 to $\left.0.40 \mathrm{~d}^{-1}\right)$ than in the absence of a cryptomonad strain $\left(0.011 \mathrm{~d}^{-1}\right)$, indicating that $M$. rubra could grow in the presence of diverse cryptomonad prey. However, M. rubra (MR-MAL01) did not grow better in the presence of cryptomonad strain CR-MAL06. Further comparisons of the growth rates of MR-MAL01 showed that cryptomonads in Clade 3 might be less favored than those in Clade 2 by the starved M. rubra. Here, we demonstrated that MR-MAL01 has preferences with regard to potential cryptomonad prey strains, suggesting that the growth of MR-MAL01 may be partially affected by the availability of preferred cryptomonad prey types.
\end{abstract}

KEY WORDS: Myrionecta rubra $\cdot$ Cryptomonads $\cdot$ Growth rates $\cdot 18$ S rRNA sequences

\section{INTRODUCTION}

The marine phototrophic ciliate Myrionecta rubra Jankowski 1976 (= Mesodinium rubrum Lohmann 1908) is a common and cosmopolitan species (Crawford 1989). The 'functionally autotrophic' ciliate (Ryther 1967, Sieburth et al. 1978) frequently forms massive blooms in eutrophicated marine environments (Taylor et al. 1971, Lindholm 1985). Using novel laboratory strains of this 'unculturable' ciliate that feeds on cryptophyte prey (Gustafson et al. 2000, Yih et al. 2004a) and bacterial cells (Myung et al. 2006), its applicability as a live feed (Yih et al. 2004b), its growth and photophysiology (Johnson \& Stoecker 2005, Hansen \& Fenchel 2006), the function and maintenance of cryptophyte plastids (Hansen \& Fenchel 2006, Johnson et al. 2006), and the phylogenetic position of M. rubra (Johnson et al. 2004) have recently been explored. Kleptoplastidy (i.e. plastids derived from ingested prey) in M. rubra has been discussed over the last few years as a means to acquire and maintain photosynthetic capacity (Gustafson et al. 2000, Yih et al. 2004a, Johnson et al. 2006). Hansen \& Fenchel (2006), however, have argued that plastids of $M$. rubra are 
really associated with a permanent symbiosis. Therefore, it is possible that the 3 reported strains of $M$. rubra might not have developed through the same paths of plastid evolution (Hansen \& Fenchel 2006).

Diverse species of cryptomonads are found in marine habitats and Myrionecta rubra might possibly feed on multiple species of cryptomonads. Thus, it appears that M. rubra may retain plastids from various cryptomonads and tend to prefer a particular type of cryptomonad. However, the preferential growth of $M$. rubra in the presence of various cryptomonads remains to be determined. To evaluate this possibility, we investigated the growth responses of $M$. rubra strain MR-MAL01, which was starved for $20 \mathrm{~d}$ and then supplied with prey cells of 6 cryptomonad strains (CRMAL01，CR-MAL02， CR-MAL03，CR-MAL04， CRMAL05, and CR-MAL06). We observed that $M$. rubra strain MR-MAL01 exhibited a preference for particular strains among the 6 cryptomonad strains, and that the growth of $M$. rubra may occasionally be influenced by the availability of its preferred prey types in the phototrophic plankton community.

\section{MATERIALS AND METHODS}

Clonal cultures of cryptomonads and Myrionecta rubra. Clonal cultures of $M$. rubra MR-MAL01 and a cryptomonad CR-MAL01 were established and maintained as described in a recent study (Yih et al. 2004a). Briefly, single cells were isolated using Pasteur capillary pipettes from water samples collected at Gomso Bay, Korea $\left(35^{\circ} 40^{\prime} \mathrm{N}, 126^{\circ} 40^{\prime} \mathrm{E}\right)$. Each isolated $M$. rubra MR-MAL01 cell was washed 3 times with enriched f/2 seawater media, and subsequently incubated under continuous illumination. Every 5 to $6 \mathrm{~d}$, cryptophyte prey (CR-MAL01) were added to readjust the proportion of cryptophytes to $M$. rubra MR-MAL01 cells to a 5:1 ratio. The other 5 cryptomonad strains were also cultured by isolating single cells from samples of Korean coastal waters (see Table 1). All the strains were kept at $15^{\circ} \mathrm{C}$ and 30 psu in enriched $\mathrm{f} / 2$ seawater media (Guillard \& Ryther 1962). The same seawater was always used for the repeated subculturing of cryptomonads and M. rubra MR-MAL01 in order to ensure that the cultures were maintained under similar water conditions. The cryptomonads were provided a continuous illumination of $25 \mu \mathrm{E} \mathrm{m} \mathrm{m}^{-2} \mathrm{~s}^{-1}$, whereas $M$. rubra MR-MAL01 was provided with an illumination of $60 \mu \mathrm{E} \mathrm{m} \mathrm{m}^{-2} \mathrm{~s}^{-1}$ (Yih et al. 2004a). No cultures were axenic. However, the contribution of bacterivory to the growth of $M$. rubra MR-MAL01 in terms of cell carbon (ingestion of 53 bacteria $\mathrm{h}^{-1}$ by 1 ciliate; Myung et al. 2006) was estimated to be not significant. Further, our vast preliminary data indicated that our cryptomonad strains did not take up fluorescentlylabeled (i.e. 5-[4,6-dichlorotriazin-2-yl] aminofluorescein [DTAF]) bacteria.

Growth rates of Myrionecta rubra and cryptomonad prey species. The experimental $M$. rubra culture was starved of cryptomonad prey for $20 \mathrm{~d}$ and used in a batch culture experiment to estimate growth rate. After 20 d, each experimental cryptomonad culture $\left(1.0 \times 10^{4}\right.$ cells $\left.\mathrm{ml}^{-1}\right)$ was offered as prey to the starved $M$. rubra culture $\left(1.0 \times 10^{3}\right.$ cells $\left.\mathrm{ml}^{-1}\right)$ under

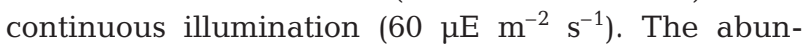
dances of $M$. rubra and its cryptomonad prey in subsamples obtained daily from duplicate $500 \mathrm{ml}$ polycarbonate (PC) bottles were determined by counting the cells in $1 \mathrm{ml}$ Sedgewick-Rafter slides.

The specific growth rates of Myrionecta rubra and the cryptomonad prey obtained from each experimental bottle were calculated by averaging the daily growth rates (DGR) using:

$$
\mathrm{DGR}=\ln \left(S_{t 2} / S_{t 1}\right) /\left(t_{2}-\mathrm{t}_{1}\right)
$$

where $t_{2}-t_{1}=1 \mathrm{~d}$, and $\mathrm{S}_{t 1}$ and $\mathrm{S}_{t 2}$ are cell concentrations in consecutive subsamples.

Molecular sequencing. Nucleic acids were extracted and purified using hexadecyltrimethyl ammonium bromide (CTAB) and organic extractions, as described by Ausubel et al. (1999). Cells were harvested from 100 to $250 \mathrm{ml}$ samples of the cultures by centrifugation $(10 \mathrm{~min}$ at $12000 \times \mathrm{g}$ ). Amplification of $18 \mathrm{~S}$ rRNA genes was performed using standard PCR protocols with eukaryote-specific primers EukA and EukB (Medlin et al. 1988). The reaction mixture contained 50 to $100 \mathrm{ng}$ of DNA, $0.2 \mathrm{mM}$ deoxynucleoside triphosphate, each primer at a concentration of $0.3 \mu \mathrm{M}, 10 \mathrm{mM}$ Tris- $\mathrm{HCl}$ (pH 9.0), $1.5 \mathrm{mM} \mathrm{MgCl}_{2}, 40 \mathrm{mM} \mathrm{KCl}$, and $2.5 \mathrm{U}$ Taq DNA polymerase (Bioneer). PCR-amplification was performed according to the following protocol: an initial denaturation step $\left(5 \mathrm{~min}, 94^{\circ} \mathrm{C}\right.$ ) was followed by 30 cycles consisting of denaturation $\left(45 \mathrm{~s}, 94^{\circ} \mathrm{C}\right)$, annealing $\left(1 \mathrm{~min}, 55^{\circ} \mathrm{C}\right)$, and extension $\left(3 \mathrm{~min}, 72^{\circ} \mathrm{C}\right)$, with a final 10 min extension step at $72^{\circ} \mathrm{C}$. The size of the PCR products was approximately $1.5 \mathrm{~kb}$ for Myrionecta rubra strain MR-MAL01 and approximately $1.8 \mathrm{~kb}$ for the 6 cryptomonad strains CR-MAL01, CR-MAL02, CR-MAL03, CR-MAL04, CR-MAL05, and CR-MAL06, and this was confirmed by agarose gel electrophoresis. The amplified products were purified using a PCR purification kit (Bioneer) according to the manufacturer's instructions, and then ligated into the prepared pGEM-T Easy vector supplied with the pGEM-T Easy Vector System (Promega) according to the manufacturer's protocols. Plasmid DNA from putative positive colonies was harvested using a Bioneer plasmid purification kit (Bioneer). Typically, 5 to 8 positive clones from each strain were partially sequenced using the T7 
promoter sequencing primer (i.e. 5'-AATACGACTCACTATAG-3') derived from the cloning vector, and all partial sequences (approximately $700 \mathrm{bp}$ ) were subsequently identified by a BLASTN search. They were putatively identified as members of cryptomonads. Among the positive clones, including the identified partial sequences, 1 to 2 positive clones were selected and completely sequenced using both the SP6 promoter sequencing primer (i.e. 5'-ATTTAGGTGACACTATAG-3') derived from the cloning vector and a eukaryote-specific primer (i.e. 1209R; 5'-GGGCATCACAGACCTG-3'). Sequencing was performed with an Applied Biosystems automated sequencer (ABI 3730xl) at Macrogen in ROK. The 18S rRNA gene sequences from the cultured samples were deposited in GenBank under the following accession numbers: MR-MAL01 (EF195734), CR-MAL01 (EF195735), CRMAL02 (EF195736), CR-MAL03 (EF195737), CRMAL04 (EF195738), CR-MAL05 (EF195739), and CRMAL06 (EF195733).

Phylogenetic analysis. The 18S rRNA gene sequences obtained from the cultures were compared with the sequences of related taxa obtained from the GenBank database using a BLASTN search. The sequences were manually aligned using the $18 \mathrm{~S}$ rRNA secondary structure (Van de Peer et al. 2000). Phylogenetic analyses were performed using the following 2 data sets: (1) 33 representative sequences in alveolates, and (2) 31 representative sequences in cryptomonads. Only homologous positions in the $18 \mathrm{~S}$ rRNA gene sequences were used for all the phylogenetic analyses. Prorocentrum micans and Glucocystophyta (Cyanophora paradoxa and Glaucocystis nostochinearum) were used as outgroups for the alveolates and cryptomonads, respectively. The 1344 position of unambiguously aligned sites was retained for phylogenetic analysis of alveolates and outgroups. For the phylogenetic analysis of cryptomonads, the conserved 1524 position was considered as an 'unambiguously aligned site'. These alignments are available on request.

Phylogenetic trees were inferred by the maximum likelihood (Felsenstein 1981) method using PAUP* 4b10 (Swofford 1998) and by Bayesian analysis using MRBAYES 3.0 (Huelsenbeck \& Ronquist 2001). For the analyses of alveolates and cryptomonads, the generaltime reversible + gamma + I and Tamura-Nei + gamma + I models, respectively, were selected using Modeltest version 3.04 (Posada \& Crandall 1998). Parameter values for the likelihood analysis were estimated from a test tree obtained using PAUP*. For each maximum likelihood analysis, the best tree was found using 20 random additions and tree bisection-reconstruction (TBR) branch-swapping, and a 200 replicate bootstrap analysis was performed. Posterior probabilities of phylogenetic trees under the Tamura-Nei + gamma + I and general-time reversible + gamma + I models were estimated using MRBAYES 3.0 (Huelsenbeck \& Ronquist 2001). Four simultaneous Markov Chain Monte Carlo (MCMC) chains were run for 1000000 generations, and were sampled every 500 generations (burnin 200000 generations).

\section{RESULTS AND DISCUSSION}

\section{Phylogenetic analysis of temperate Myrionecta rubra strain MR-MAL01}

The size of the 18S rRNA gene (1552 bp) in Myrionecta rubra MR-MAL01 was similar to that in $M$. rubra GenBank Accession No. AY587129 (1548 bp) and Mesodinium pulex (1543 bp), but much shorter than those in other alveolates (average $1712 \mathrm{bp}$, data not shown). The 18S rRNA genes of strains $M$. rubra MR-MAL01, M. rubra AY587129 and M. pulex shared the identical oligomer sequence (i.e. 5'-TTGGACCGGACGAAGAC-3') that is found solely in the 18S rRNA genes of M. rubra (AY587129) and M. pulex (Johnson et al. 2004). The $18 \mathrm{~S}$ rRNA gene sequence of $M$. rubra MR-MAL01 was extremely similar $(99.6 \%)$ to that of M. rubra AY587129 (data not shown). In the phylogenetic tree (Fig. 1), the M. rubra strain MR-MAL01 was placed within the Mesodiniidae, with high bootstrap support (maximum likelihood: 100\%) and posterior probability of 1 , and formed a clade with $M$. rubra AY587129 with high bootstrap support (98\%) and posterior probability of 1 . Our strain consistently conformed to the behavioral and morphological characteristics of M. rubra (Lynn \& Small 2002).

\section{Phylogenetic analysis of six experimental cryptomonad strains}

Cryptomonads, including the 6 experimental strains, were divided into 7 major lineages in a phylogenetic tree with moderately strong bootstrap support (maximum likelihood $71 \%$ ) or high posterior probability (0.95, Fig. 2), including 2 lineages comprising the monospecific genera Falcomonas and Proteomonas, as previously reported for the phylogenetic tree of crytomonads (Clay \& Kugrens 1999, Hoef-Emden et al. 2002). In addition, phagotrophic Goniomonas truncata demonstrated the highest divergence of all sequences in the phylogenetic tree, and represented a basal taxon within the crytomonads (Clay \& Kugrens 1999, HoefEmden et al. 2002). Phylogenetic analysis of the aligned 18S rRNA sequences suggested that our 6 strains differed from each other, and they did not fall 


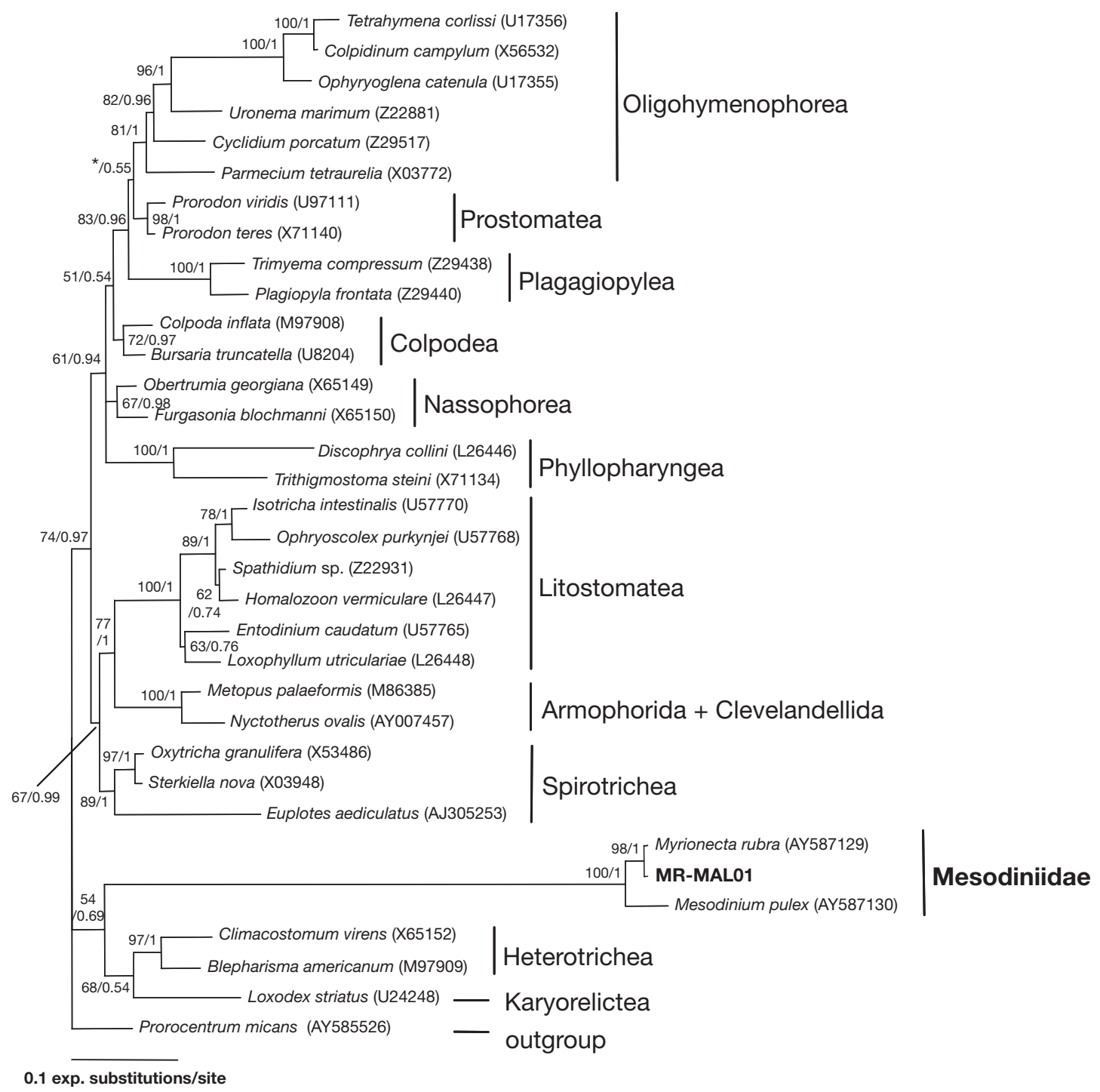

Fig. 1. 18S rRNA gene tree showing the phylogenetic position of Myrionecta rubra strain MR-MAL01 relative to 32 other alveolates. Prorocentrum micans was used as the outgroup. Bootstrap values ( $>50 \%$ ) from the maximum likelihood method (ML; 200 replicates) and Bayesian posterior probability (MB) are indicated at nodes (presented in the order ML/MB). Accession numbers of each taxon presented in parentheses. *: bootstrap value of $<50 \%$ in ML analysis

within any established species of the cryptomonad order Pyrenomonadales (Fig. 2). The strains CRMAL01， CR-MAL02, CR-MAL04, and CR-MAL05 were included in cryptomonad Clade 2, while the strains CR-MAL06 and CR-MAL03 were included in cryptomonad Clade 3 (Fig. 2). Cryptomonad Clade 2 is divided into the following 4 lineages with high bootstrap support $(98 \%)$ or a posterior probability of 1 : (1) CR-MAL01, CR-MAL02, Teleaulax amphioxeia, CR-MAL05, Plagioselmis prolonga, (2) CR-MAL04, (3) Teleaulax acuta, and (4) Germinigera cryophila. Cryptomonad Clade 3 is divided into the following 2 lineages with high bootstrap support $(98 \%)$ or a posterior probability of 1: (1) Pyrenomonas salina, CR-
MAL06, Rhodomonas abbreviata, Rhodomonas sp. M1480, Rhinomonas pauca, CR-MAL03, and (2) Storeatula major (Fig. 2). Our cryptomonad strains were included in cryptomonad Clades 2 and 3, which are known to be widely distributed in marine ecosystems (Hoef-Emden et al. 2002).

\section{Growth response of Myrionecta rubra to different cryptomonad strains}

The 20 d starved Myrionecta rubra MR-MAL01 exhibited exponential growth in the bispecies culture bottles for $6 \mathrm{~d}$ in response to all but one (i.e. CR- 


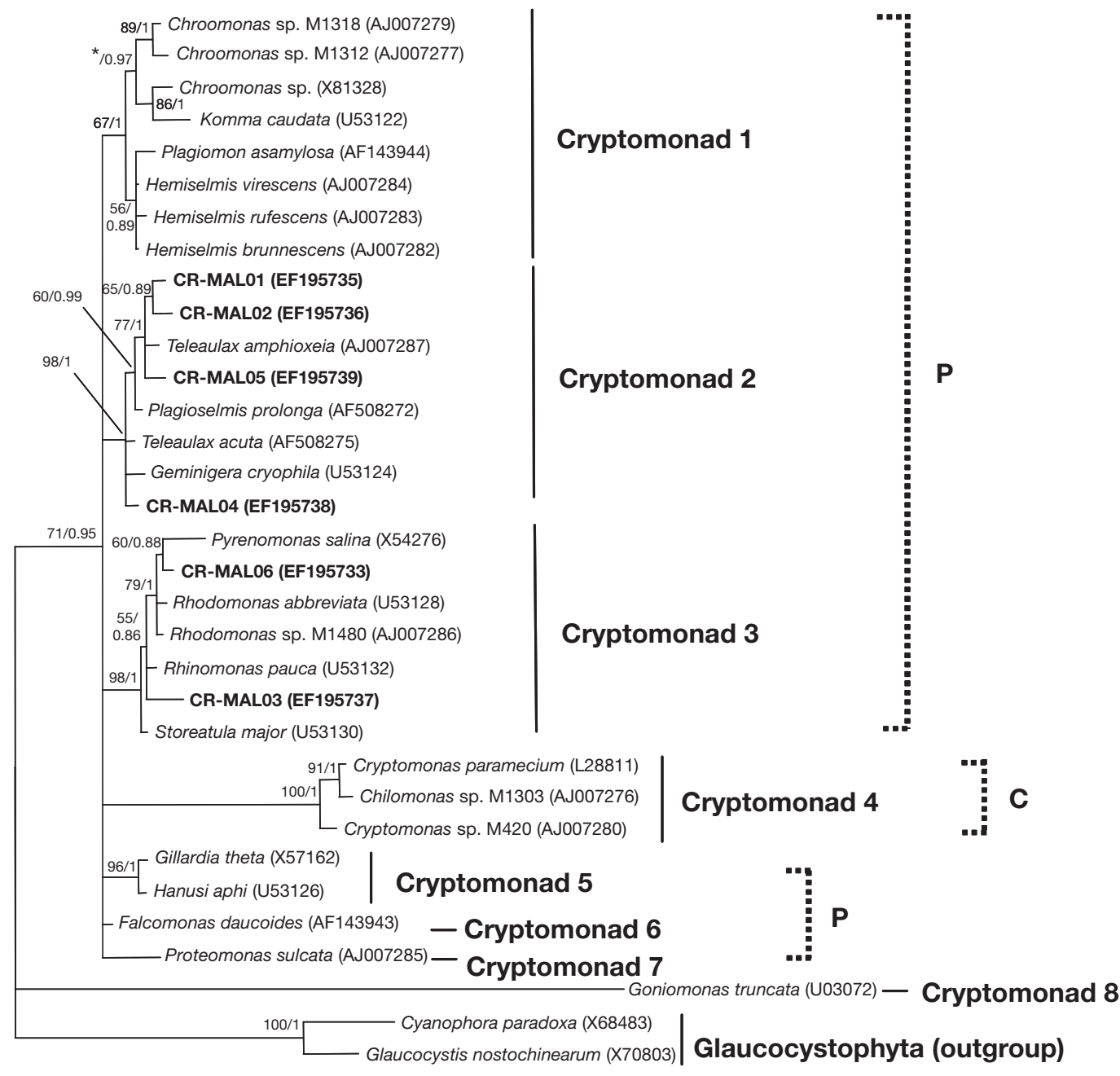

0.1 exp. Substitutions/site

Fig. 2. 18S rRNA gene tree showing the phylogenetic position of 6 cryptomonad strains (CR-MAL01, CR-MAL02, CR-MAL03, CR-MAL04, CR-MAL05, and CR-MAL06) relative to 25 other cryptomonads. Glaucocystophyta was used as the outgroup. Bootstrap values $(>50 \%$ ) from maximum likelihood (ML; 200 replicates) and Bayesian posterior probability (MB) are indicated at nodes (presented in order ML/MB). Accession numbers of each taxon presented in parentheses. P: Pyrenomonadales; C: Cryptomonadales; G: Goniomonadida; *: bootstrap value of $<50 \%$ in ML analysis

MAL06) of the cryptomonad prey strains (Fig. 3). The growth rates of $M$. rubra MR-MAL01 gradually decreased in the presence of different cryptomonad prey as follows: CR-MAL05 $\left(0.40 \mathrm{~d}^{-1}\right)$, CR-MAL02 $\left(0.27 \mathrm{~d}^{-1}\right)$, CR-MAL01 $\left(0.20 \mathrm{~d}^{-1}\right)$, CR-MAL04 $\left(0.17 \mathrm{~d}^{-1}\right)$, and CR-MAL03 (0.16 $\left.\mathrm{d}^{-1}\right)$ (Table 1). Simultaneously, the prey species exhibited considerable intrinsic growth (i.e. $\mu \mathrm{d}^{-1}$ of 0.31 to 0.85 ), which confirms the prey-replete condition of the experimental ciliate during the $6 \mathrm{~d}$ period (Table 1; Yih et al. 2004a).

Recently, Gustafson et al. (2000) found that $28 \mathrm{~d}$ starved Myrionecta rubra AY587129 obtained from Antarctic seawater grew better in the presence of Geminigera cf. cryophila (formerly Teleaulax acuta,
Johnson et al. 2006) than in its absence (0.13 vs. $0.06 \mathrm{~d}^{-1}$ ). In addition, Yih et al. (2004a) demonstrated that the growth rate of $14 \mathrm{~d}$ starved $M$. rubra MRMAL01 $\left(0.52 \mathrm{~d}^{-1}\right)$ was 1.4 times faster following the addition of cryptomonad prey strain CR-MAL01 than that in its absence $\left(0.36 \mathrm{~d}^{-1}\right)$. Likewise, our experiments consistently showed that the $20 \mathrm{~d}$ starved $M$. rubra strain MR-MAL01 obtained from temperate coastal seawater grew better in the presence of cryptomonad strains CR-MAL01, CR-MAL02, CR-MAL04, and CR-MAL05 (0.17 to $\left.0.40 \mathrm{~d}^{-1}\right)$ than in the absence of a cryptomonad strain $\left(0.011 \mathrm{~d}^{-1}\right.$, Fig. 3, Table 1). Thus, it seems that the greater the pre-starvation period of M. rubra MR-MAL01, the slower its growth rate, even 


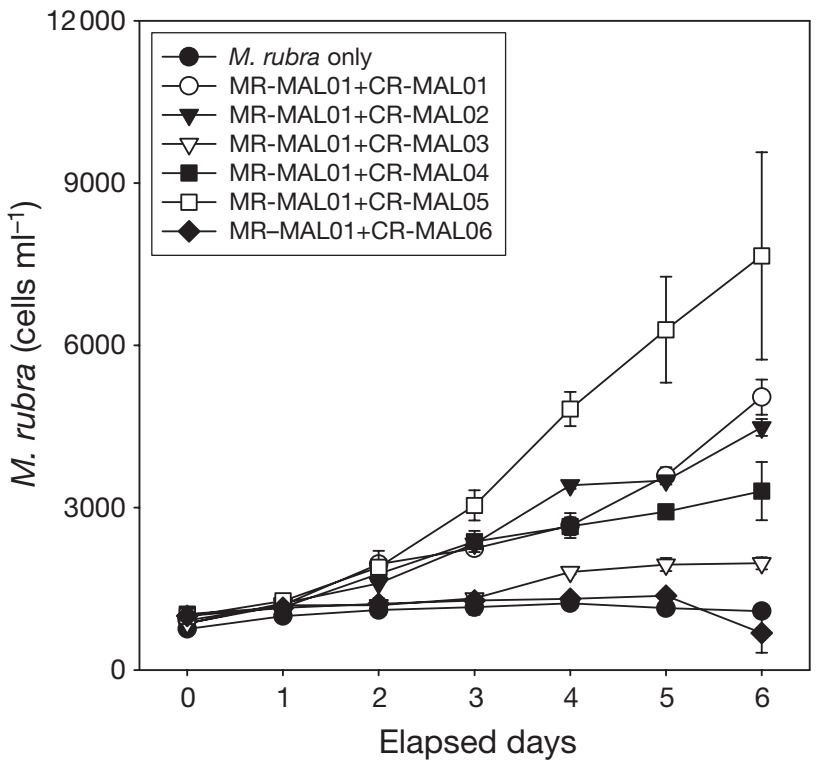

Fig. 3. Myrionecta rubra. Change in abundances of strain MR-MAL01, starved for $20 \mathrm{~d}$ then incubated in the presence of CR-MAL01，CR-MAL02，CR-MAL03，CR-MAL04，CRMAL05, and CR-MAL06, and in the absence of any cryptomonad strain. Error bars $= \pm 1 \mathrm{SD}$

when resupplied with cryptomonad prey (Johnson \& Stoecker 2005).

\section{Preferential growth of Myrionecta rubra (MR-MAL01) according to cryptomonad strain}

Interestingly, the growth rate of Myrionecta rubra MR-MAL01 in the presence of cryptomonad strain CRMAL06 (mean \pm SD $=0.039 \pm 0.034 \mathrm{~d}^{-1}$ ) was indistinguishable from that in the absence of cryptomonads $\left(\right.$ mean $\pm \mathrm{SD}=0.011 \pm 0.014 \mathrm{~d}^{-1}, t$-test, $\left.\mathrm{p}>0.05\right)$, essentially indicating that the ciliate growth was not en- hanced. Similarly, M. rubra MR-MAL01 demonstrated only a slightly elevated level of growth in the presence of cryptomonad strain CR-MAL03 (mean $\pm \mathrm{SD}=$ $0.162 \pm 0.031 \mathrm{~d}^{-1}$ ) compared with the control (no addition of cryptomonad, Fig. 3, Table 1). Our hypothesis is that the starved $M$. rubra MR-MAL01 favored cryptomonads in Clade 3 to a lesser extent than cryptomonads in Clade 2. Further comparisons of the growth rates of $M$. rubra MR-MAL01 revealed that the growth rates gradually decreased in the presence of Clade 2 cryptomonad prey in the following order: CR-MAL05 $\left(0.40 \mathrm{~d}^{-1}\right)$, CR-MAL02 $\left(0.27 \mathrm{~d}^{-1}\right)$, CR-MAL01 $\left(0.20 \mathrm{~d}^{-1}\right)$, and CR-MAL04 (0.17 $\left.\mathrm{d}^{-1}\right)$ (Table 1), even though incubation conditions were identical (i.e. starvation time and initial density of MR-MAL01, temperature, salinity, light intensity, and the ratio of MR-MAL01 to prey). Therefore, our results indicate that $M$. rubra MRMAL01 prefers some cryptomonad prey over others, and the growth of $M$. rubra MR-MAL01 is partially influenced by the availability of the different cryptomonad prey type. In laboratory cultures, sustained growth of $M$. rubra over generations requires that the ciliate ingest Geminigera cf. cryophila (Johnson \& Stoecker 2005, Johnson et al. 2006), Teleaulax sp. (Hansen \& Fenchel 2006), or 5 different cryptomonad strains (this study, Yih et al. 2004a) mostly belonging to cryptomonad Clade 2 of our phylogenetic tree. Therefore, one of the reasons for the failure of many earlier attempts to culture $M$. rubra might have been the choice of inappropriate cryptophyte prey; many culture collections comprise a majority of cryptomonad Clade 3 strains.

Finally, no relationship was found between the growth rates of Myrionecta rubra MR-MAL01 and the intrinsic growth rates $\left(0.31\right.$ to $0.85 \mathrm{~d}^{-1}$, Table 1$)$ or biovolumes (82 to $294 \mathrm{\mu m}^{3}$, Table 1) of the cryptomonad prey (data not shown). It is possible that the preferential growth of the starved M. rubra MR-MAL01 could be controlled by other factor(s). After reviewing the

Table 1. Myrionecta rubra. Growth rates with and without the addition of cryptomonad strains, intrinsic growth rates, estimated biovolume, and sources of cryptomonad strains. na: not available

\begin{tabular}{|c|c|c|c|c|c|c|c|}
\hline Strain & $\begin{array}{l}\text { Growth rate of } \\
M . \text { rubra } \\
\left(\text { mean } \pm \mathrm{SD}, \mathrm{d}^{-1}\right)\end{array}$ & $\begin{array}{l}\text { Growth rate of } \\
\text { cryptomonads } \\
\left(\text { mean } \pm \mathrm{SD}, \mathrm{d}^{-1}\right)\end{array}$ & $\begin{array}{c}\text { Biovolume of } \\
\text { cryptomonads }^{\mathrm{a}} \\
\left(\mu \mathrm{m}^{3}\right)\end{array}$ & $\begin{array}{r}\text { In } \\
\text { temp. } \\
\left({ }^{\circ} \mathrm{C}\right)\end{array}$ & $\begin{array}{l}\text { situ } \\
\text { salinity } \\
\text { (psu) }\end{array}$ & Latitude, longitude & Source \\
\hline CR-MAL01 & $0.20 \pm 0.000$ & $0.63 \pm 0.096$ & 111 & 7.8 & 30.1 & $35^{\circ} 35^{\prime} \mathrm{N}, 126^{\circ} 36^{\prime} \mathrm{E}$ & Gomso Bay, Korea \\
\hline CR-MAL02 & $0.27 \pm 0.055$ & $0.79 \pm 0.069$ & 106 & 12 & 30.3 & $35^{\circ} 35^{\prime} \mathrm{N}, 126^{\circ} 36^{\prime} \mathrm{E}$ & Gomso Bay, Korea \\
\hline CR-MAL03 & $0.16 \pm 0.031$ & $0.61 \pm 0.006$ & 82 & 10.5 & 30.8 & $36^{\circ} 49^{\prime} \mathrm{N}, 126^{\circ} 10^{\prime} \mathrm{E}$ & Taean, Korea \\
\hline CR-MAL04 & $0.17 \pm 0.001$ & $0.31 \pm 0.003$ & 294 & 7.5 & 31.6 & $35^{\circ} 05^{\prime} \mathrm{N}, 126^{\circ} 09^{\prime} \mathrm{E}$ & Shinan, Korea \\
\hline CR-MAL05 & $0.40 \pm 0.002$ & $0.85 \pm 0.038$ & 102 & 5.4 & 20.6 & $35^{\circ} 58^{\prime} \mathrm{N}, 126^{\circ} 35^{\prime} \mathrm{E}$ & Gunsan, Korea \\
\hline CR-MAL06 & $0.04 \pm 0.034$ & $0.75 \pm 0.067$ & 215 & na & na & na & na \\
\hline No addition & $0.01 \pm 0.014$ & na & na & na & na & na & na \\
\hline
\end{tabular}


present study, Johnson et al. (2007) reported that plastid division of the cryptomonad Geminigera cryophila in M. rubra AY587129 was induced by the sequestered cryptomonad nuclei. Likewise, loss of the cryptomonad nuclei leads to decreases in the growth rates of $M$. rubra AY587129. Thus, it is possible that the retention time of the nuclei in M. rubra MR-MAL01 may differ according to the donor prey species. The retention times of the sequestered nuclei of various cryptomonad species are currently unknown; however, this merits further examination, particularly since the fate of the Geminigera cryophila nuclei in M. rubra AY587129 has been uniquely examined thus far.

\section{Implications of kleptoplastidy and the feeding preferences of Myrionecta rubra}

It is still highly controversial whether Myrionecta rubra ingests cryptophyte cells for the nutritional supply or for kleptoplastidy (Hansen \& Fenchel 2006, Park et al. 2006). The plastids of cryptophyte origin in $M$. rubra were believed to be cryptophyte symbionts for a long time (Lohmann 1908, Fonds \& Eisma 1967, Ryther 1967), probably owing to repeated failed culture attempts. However, by using monoxenic cultures, it was recently shown that the ciliate actually ingests cryptophyte cells (Yih et al. 2004a, Hansen \& Fenchel 2006) in order to retain the photosynthetic capacity of plastids derived from the prey cryptophytes, which may last up to $30 \mathrm{~d}$ (Johnson \& Stoecker 2005, Johnson et al. 2007).

If Myrionecta rubra is kleptoplastidic, then the successful acquisition of plastids should be important for its sustained growth (Yih et al. 2004a). In that case, the rapidly growing free-living cells of $M$. rubra MRMAL01 require the following criteria for their growth: (1) cryptophyte prey, (2) that available cryptophyte members include CR-MAL05, CR-MAL02, and CRMAL01 rather than the other cryptomonads of the present study (Table 1), and finally, (3) the maintenance of high photosynthetic rates, supported by the retained plastids. Moreover, it is likely that the preferential consumption of certain cryptophyte prey potentially leads to changes in cryptophyte communities in diverse marine environments, particularly during the $M$. rubra blooming period.

In conclusion, we demonstrated that the growth rate of Myrionecta rubra MR-MAL01 differed markedly when provided with various cryptomonad prey strains (i.e. CR-MAL01, CR-MAL02, CR-MAL03, CR-MAL04, and CR-MAL05). The 5 prey strains were grouped into 2 cryptomonad clades, which represent a much wider range of prey than previously thought. Furthermore, the growth rate of $M$. rubra MR-MAL01 may be influenced by the availability of specific prey types.
Acknowledgements. This research was supported by the NRL program of KOSEF (M10300000314-06J0000-31410) funded by MOST, the BK21 project (to B.C.C.), and the BK21 project of Korea MOE \& HRD (to W.Y.).

\section{LITERATURED CITED}

Ausubel FM, Brent R, Kingston RE, Moore DD, Seidman JG, Smith JA, Struhl K (1999) Current protocols in molecular biology. John Wiley \& Sons, New York

Clay BL, Kugrens P (1999) Characterization of Hemiselmis amylosa sp. nov. and phylogenetic placement of the bluegreen cryptomonads $H$. amylosa and Falcomonas daucoides. Protist 150:297-310

Crawford DW (1989) Mesodinium rubrum: the phytoplankter that wasn't. Mar Ecol Prog Ser 58:161-174

Felsenstein J (1981) Evolutionary trees from DNA sequences: a maximum likelihood approach. J Mol Evol 17:368-376

Fonds M, Eisma D (1967) Upwelling water as a possible cause of red plankton bloom along the Dutch Coast. Neth J Sea Research 3:458-463

Guillard RRL, Ryther JH (1962) Studies of marine planktonic diatoms, I. Cyclotella nana Hustedt and Detonula confervacea (Cleve) Gran. Can J Microbiol 8:229-239

Gustafson DE, Stoecker DK, Johnson MD, Van Heukelem WF, Snaider K (2000) Cryptophyte algae are robbed of their organelles by the marine ciliate Mesodinium rubrum. Nature 405:1049-1052

Hansen PJ, Fenchel T (2006) The bloom-forming ciliate Mesodinium rubrum harbours a single permanent endosymbiont. Mar Biol Res 2:169-177

Hillebrand H, Dürselen CD, Kirschtel D, Pollingher U, Zohary $\mathrm{T}$ (1999) Biovolume calculation for pelagic and benthic microalgae. J Phycol 35:403-424

Hoef-Emden K, Margin B, Melkonian M (2002) Nuclear and nucleomorph SSU rDNA phylogeny in the Cryptophyta and the evolution of cryptophyte diversity. J Mol Evol 55: 161-179

Huelsenbeck JP, Ronquist F (2001) MrBAYES: Bayesian inference of phylogenetic trees. Bioinformatics 17:754-755

Johnson MD, Stoecker DK (2005) Role of feeding in growth and photophysiology of Myrionecta rubra. Aquat Microb Ecol 39:303-312

Johnson MD, Tengs T, Oldach DW, Delwiche CF, Stoecker DK (2004) Highly divergent SSU rRNA genes found in the marine ciliates Myrionecta rubra and Mesodinium pulex. Protist 155:347-359

Johnson MD, Tengs T, Oldach D, Stoecker DK (2006) Sequestration, performance, and functional control of cryptophyte plastids in the ciliate Myrionecta rubra (Ciliophora). J Phycol 42:1235-1246

Johnson MD, Oldach D, Delwiche CF, Stoecker DK (2007) Retention of transcriptionally active cryptophyte nuclei by the ciliate Myrionecta rubra. Nature 445:426-428

Lindholm T (1985) Mesodinium rubrum-a unique photosynthetic ciliate. Adv Aquat Microb 3:1-48

Lohmann H (1908) Untersuchung zur Feststellung des vollständigen Gehaltes des Meeres an Plankton. Wiss Meeresunters Kiel 10:129-370

Lynn DH, Small EB (2002) Phylum Ciliophora. In: Lee JJ, Leedale GF, Bradbury P (eds) An illustrated guide to the Protozoa. Society of Protozoologists, Lawrence, KS, p 477-478

Medlin L, Elwood HJ, Stickel S, Sogin ML (1988) The characterization of enzymatically amplified eukaryotic 16S-like rRNA coding regions. Gene 71:491-499 
Myung G, Yih W, Kim HS, Park JS, Cho BC (2006) Ingestion of bacterial cells by the marine photosynthetic ciliate Myrionecta rubra. Aquat Microb Ecol 44:175-180

Park MG, Kim S, Kim HS, Myung G, Kang YG, Yih W (2006) First successful culture of the marine dinoflagellate Dinophysis acuminata. Aquat Microb Ecol 45:101-106

Posada D, Crandall KA (1998) Modeltest: testing the model of DNA substitution. Bioinformatics 14:817-818

Ryther JH (1967) Occurrerce of red water off Peru. Nature 214:1318-1319

Sieburth JM, Smetacek V, Lens F (1978) Pelagic ecosystem structure: heterotrophic compartments of the plankton and their relationship to plankton size fractions. Limnol Oceanogr 23:1256-1263

Swofford DL (1998) PAUP* 4.0. Sinauer Associates, Sunderland, MA

Editorial responsibility: Fereidoun Rassoulzadegan, Villefranche-sur-Mer, France
Taylor FJR, Blackbourn DJ, Blackbourn J (1971) The redwater ciliate Mesodinium rubrum and its 'incomplete symbionts': a review including new ultrastructural observations. J Fish Res Board Can 28:391-407

Van de Peer Y, De Rijk P, Wuyts J, Winkelmans T, De Wachter R (2000) The European small subunit ribosomal RNA database. Nucleic Acids Res 28:175-176

Yih W, Kim HS, Jeong HJ, Myung G, Kim YG (2004a) Ingestion of cryptophyte cells by the marine photosynthetic ciliate Mesodinium rubrum. Aquat Microb Ecol 36: 165-170

Yih W, Kim HS, Myung G, Kim YG (2004b) Rapid feeding on live organisms of the phototrophic ciliate Mesodinium rubrum by Farrer's scallop Chlamys farreri. J Mar Biotechnol 6:142-145

Submitted: January 16, 2007; Accepted: March 31, 2007

Proofs received from author(s): May 25, 2007 